\title{
Changes in level of household car ownership: the role of life events and spatial context
}

\author{
Ben Clark $\cdot$ Kiron Chatterjee $\cdot$ Steve Melia
}

Published online: 5 March 2015

(C) The Author(s) 2015. This article is published with open access at Springerlink.com

\begin{abstract}
Recent longitudinal studies of household car ownership have examined factors associated with increases and decreases in car ownership level. The contribution of this panel data analysis is to identify the predictors of different types of car ownership level change (zero to one car, one to two cars and vice versa) and demonstrate that these are quite different in nature. The study develops a large scale data set $(n=19,334)$, drawing on the first two waves (2009-2011) of the UK Household Longitudinal Study (UKHLS). This has enabled the generation of a comprehensive set of life event and spatial context variables. Changes to composition of households (people arriving and leaving) and to driving licence availability are the strongest predictors of car ownership level changes, followed by employment status and income changes. Households were found to be more likely to relinquish cars in association with an income reduction than they were to acquire cars in association with an income gain. This may be attributed to the economic recession of the time. The effect of having children differs according to car ownership state with it increasing the probability of acquiring a car for non-car owners and increasing the probability of relinquishing a car for two car owners. Sensitivity to spatial context is demonstrated by poorer access to public transport predicting higher probability of a non-car owning household acquiring a car and lower probability of a one-car owning household relinquishing a car. While previous panel studies have had to rely on comparatively small samples, the large scale nature of the UKHLS has provided robust and comprehensive evidence of the factors that determine different car ownership level changes.
\end{abstract}

Keywords Car ownership - Dynamics - Life events · Longitudinal · Panel data · Spatial context

B. Clark · K. Chatterjee $(\bowtie) \cdot$ S. Melia

Centre for Transport and Society, Department of Geography and Environmental Management,

University of the West of England, Bristol BS16 1QY, UK

e-mail: kiron.chatterjee@uwe.ac.uk 


\section{Introduction}

The acquisition of a car can be considered to be an indicator of a subsequent commitment to car use and is therefore seen as an important determinant of wider travel behaviour. Recent studies in this area have focused on understanding the dynamic nature of household car ownership and there is also interest in the relationship between major life events (like moving home or changing jobs) and travel behaviour changes of various types. The hypothesis is that people are more likely to reconsider their transport resources and travel routines at the time of major life events. This paper presents an empirical analysis of panel data from the new UK Household Longitudinal Study (UKHLS) which examines the role of life events and spatial context in changes to household car ownership.

An earlier analysis of this data set confirmed that life events are associated with higher likelihoods of general increases and decreases in car ownership level (Clark et al. 2014), as reported elsewhere (e.g. Oakil et al. 2014). The contribution of this paper is to identify the determinants of different types of car ownership level change (zero to one car, one to two cars, two to one car and one to zero car). It is argued that a different combination of factors is likely to influence each of these level changes.

The paper begins with a review of studies of the dynamics of household car ownership. A research framework is then justified in relation to the literature. The analytical approach to examining household car ownership level changes using data from the first two waves of the UKHLS is then introduced, followed by an interpretation of the results of logistic regression models estimated for each car ownership level change type. The paper concludes with a discussion of the implications of the results for research and policy.

\section{Literature review}

There is a large body of literature dedicated to understanding and modelling cross-sectional variations in household car ownership. These are comprehensively dealt with elsewhere (e.g. Anowar et al. 2014). To provide the context for our empirical analysis, this review focusses specifically on what is known about the intra-individual time varying nature of household car ownership and the role of life events in the process of car ownership change.

General studies of the dynamics of household car ownership

Dargay and Vythoulkas' (1999) pseudo-panel analysis of UK households reveals a car ownership life-cycle effect. Car ownership tends to increase until the head of the household reaches the age of 50 and thereafter declines. This mirrors the traditional family life cycle through which the household size expands and contracts.

Panel studies reveal that the number of cars owned is state dependent (Hanly and Dargay 2000; Thorgersen 2006; Simma and Axhausen 2003). That is, the car ownership state in a previous time period is a strong predictor of the car ownership state in the current time period. Stability in car ownership may be partially explained by the notion of habit formation. Habits are automatically repeated behaviours with little or no conscious reconsideration of whether alternative behaviours may be as, or more effective (Verplanken et al. 1997). The acquisition of a car may encourage lifestyles and travel routines based on car use with little or no consideration of alternatives. This is evidenced by the previously observed asymmetric relationship between car ownership and income (Dargay 2001). In this analysis of data from 1970 to 1995, a rise in income was observed to be associated 
with a probable increase in the number of cars owned, while an equivalent reduction in income did not prompt an equal and opposite reduction in the number of cars owned.

\section{Household car ownership and life events}

Fried et al. (1977) suggest that behaviour is continually in a process of adaptation to changes in personal needs and environmental structures. Life events can be viewed in this context as internal forces that lead to changes in circumstance. Salomon (1983) introduced the concept of a decision hierarchy with three inter-dependent levels. Lifestyle choice is at the top level and represents the longest term decisions (e.g. family formation), below which is mobility choices (e.g. car ownership) with activity and travel choices at the lowest level. The mobility biographies framework introduced by Lanzendorf (2003) develops this idea. Lanzendorf proposes three biographical domains (lifestyle, accessibility and mobility domains) which are interlinked such that events in one domain affect the others.

These theories have provided the motivation for a growing body of empirical studies which are generating evidence of a relationship between different types of travel behaviour change and life events (see Clark et al. 2014 for a comprehensive review). Nevertheless, there remain relatively few studies that focus specifically on the relationship between life events and changes to household car ownership level. The review turns to these next.

Using data from the British Household Panel Survey for 1991-2001, Dargay and Hanly (2007) observed that there is a greater prevalence of car ownership level changes amongst households experiencing a life event from 1 year to the next (changes in household composition, employment, or residential relocation), compared to households that do not experience a life event. Prillwitz et al. (2006) used 5 year panel data from the German Socio-Economic Panel (1998-2003, $\mathrm{n}=4698)$ to estimate a binomial probit model on the propensity to gain an additional car. They found that an increase in number of adults, birth of the first child and increase in household income increase the likelihood of gaining a car. Residential relocations of different types were not found to be statistically significant, except that moving within a core urban area reduced the likelihood of gaining a car.

Yamamoto (2008) used 14 year panel data $(1984-1998, \mathrm{n}=3638)$ for households in France to estimate hazard-based duration models to predict the timing of the next vehicle transaction (replacement, disposal, acquisition) as a function of life events (increases/ decreases in the number of adults/children, changes in income and residential relocations), household composition, residential location type and age/gender of the main driver. Having children increased the probability of acquiring a car, while moving increased the probability of both disposals and acquisitions. Yamamoto also observed that the inclusion of life event covariates significantly improved model fit.

Oakil et al. (2014) conducted their own retrospective survey to generate 21 year event histories for 312 households in Utrecht (Netherlands). The sample is acknowledged to be biased towards highly educated households. They estimated mixed logit models for car relinquishments and car acquisitions and examined whether these are more likely to occur in anticipation (1 year before), simultaneously (in the same year) or following (1 year after) various life events. They found that having a child is associated with car acquisitions in anticipation of the event, while changes in employer are associated with car relinquishments simultaneously or after the event. Retirement was found to be associated with car relinquishments in anticipation of the event. Residential relocations were found to increase the likelihood of acquiring an additional car in the same year, but also reduced the likelihood of relinquishing a car after a period of 12 months. 
Rashidi et al. (2011) used three wave data from the Puget Sound Transportation Study $(1999-2002, \mathrm{n}=615)$ to estimate a vehicle transaction timing model which is conditional on household residential relocations and individual job changes occurring for both husbands and wives in the household. Taking this approach they observed that longer commuting travel times are found to increase the likelihood of changing jobs or moving home, but reduce the likelihood of changing car ownership level. Residential relocations were themselves found to be associated with increased likelihood of changing car ownership level.

Clark (2012) took an alternative inductive perspective. He administered a telephone survey of two neighbourhoods in Bristol (UK) to capture 184 respondent explanations for household car ownership level changes. Respondents provided explanations in their own words in response to the prompt "please explain why the number of cars available to you changed at this time". A categorisation of responses found that $65 \%$ of the 102 recorded car ownership level changes could be attributed to one of the following life events: a change in working circumstances; residential relocation; child birth; offspring reaching driving age; an adult joining or leaving the household; retirement.

Studies that distinguish between different car ownership level change types

Few studies have examined the different types of car ownership level changes. Dargay and Hanly (2007) observe that transitions between one and two cars are the most commonly recorded year to year, suggesting that second car ownership is more volatile than first car ownership. Roorda et al. (2009) constructed a utility function for car ownership, imputing utility from socio-economic variables. On this basis they found that the highest utility gain was experienced by carless households acquiring the first car. The gain/loss transactions were asymmetric: losing a car was associated with a larger reduction in utility than the increase in utility from gaining a car.

\section{Research framework}

Based on this assessment of the literature, a justification for the empirical study reported in this paper is as follows:

1. Car ownership level changes may be more likely to occur at the time of life events. To date studies of this relationship have either relied on small scale, retrospective surveys or larger scale panel surveys which have only considered a limited range of life events.

2. Car ownership level change types differ (e.g. zero to one car is a quite different transaction from one to two cars) and are likely to be associated with different factors, including different life events. To our knowledge, no studies have yet examined the relationship between life events and these different types of car ownership level change.

3. Evidence suggests that there is a household life-cycle effect where car ownership tends to rise as household members get older before reducing in later life. Our study also set out to explore whether the different car ownership level change types are more or less likely to occur at particular stages of life.

A generalised conceptual model for the relationship between life events and travel behaviour is shown in Fig. 1. The hypothesis made is that turning points in travel behaviour, such as change in car ownership level, are triggered by a contextual change (a life 


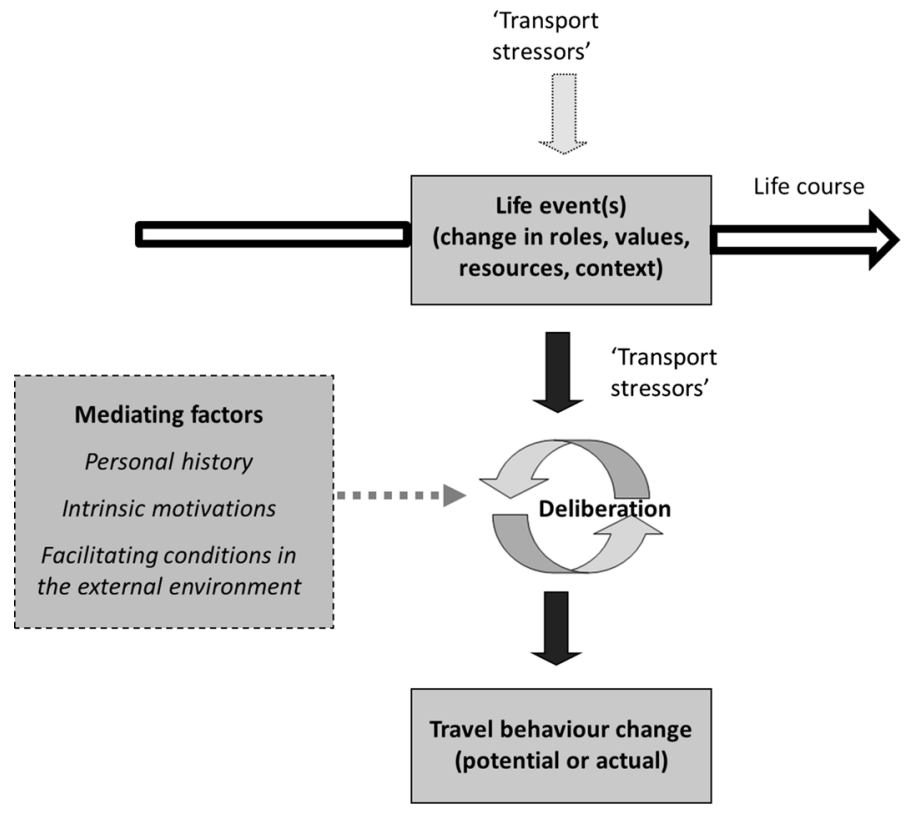

Fig. 1 Conceptual model for explaining turning points in travel behaviour

event for the purposes of our research but this could also be a change to the transport system). Life events can alter the roles that people perform within their family and social networks, alter the values people hold, alter the resources available for travel and alter the context for travel. These can create 'transport stressors', which entail discrepancies between the current transport circumstances and a desirable alternative (Miller 2005), and can change the travel mode alternatives that are available, the characteristics of travel that are considered salient and hence attitudes towards travel modes (Van der Waerden et al. 2003). Drawing on the work of Giele and Elder (1998), and later developed by Chatterjee et al. (2013), three types of mediating factor are hypothesised to play a role in the outcome on travel behaviour of contextual change. These are personal history (for example, experience in using travel modes), intrinsic motivations (for example, saving money or improving health) and facilitating conditions (for example, public transport availability).

With a specific focus on car ownership, Fig. 2 maps out how household car ownership level changes may tend to occur over the life cycle based on qualitative evidence presented in Clark (2012). The number of cars owned by a household is related to the process through which the current group of household members came together (which is marked by particular life events such as partnership formation and dissolution, having children and children reaching driving age and leaving home) and the life stages of household members and their collective car ownership needs and desires.

It should be acknowledged that the traditional family life-cycle is weakening with greater diversity in individual life development (Beaumont 2011). Nevertheless previous empirical work (Dargay and Vythoulkas 1999; Clark 2012) reveals that households with a higher number of cars are usually also the ones with a higher number of adults (and vice versa). Hence processes of family formation and dissolution are likely to retain importance. 


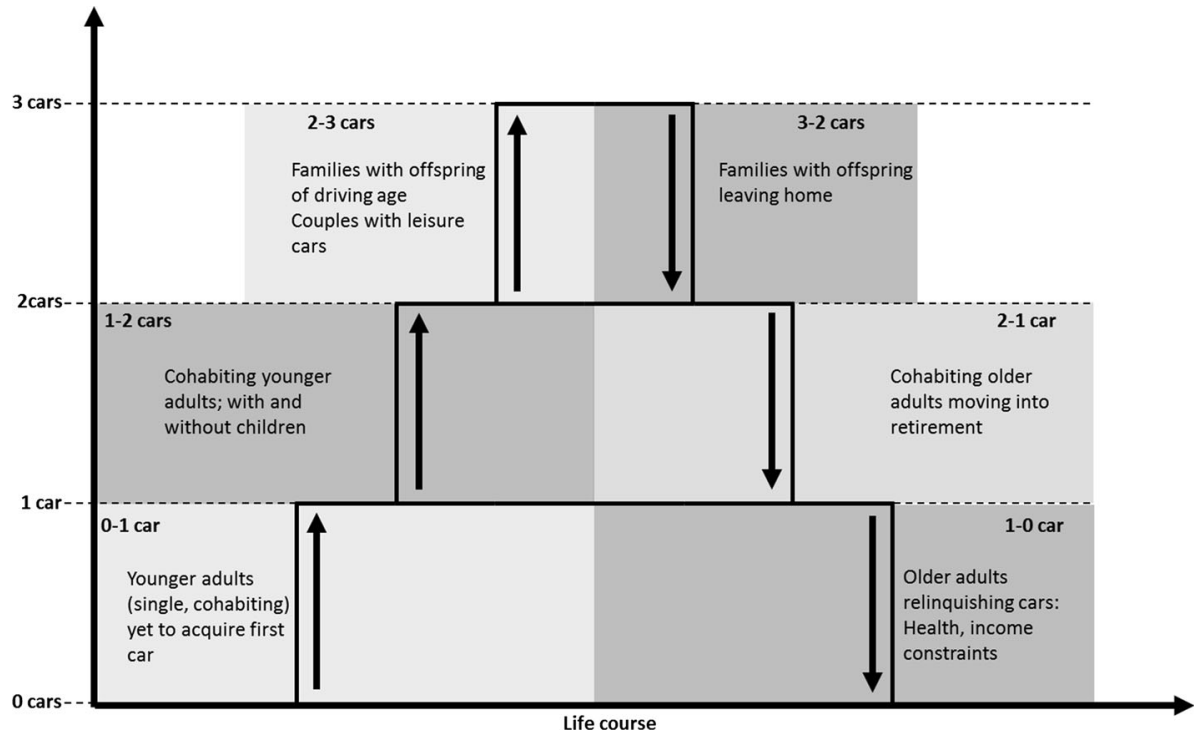

Fig. 2 Car ownership level changes and the household life cycle (Clark 2012)

The empirical analysis reported in this paper sought to test whether this conceptualisation is supported by quantitative data.

\section{Data}

The data set prepared for analysis in this study was derived from the first two waves of the UKHLS. The UKHLS started in 2009 and captures a range of social, economic and attitudinal information about the lives of members of 40,000 households. Adult household members are interviewed once per year. Given restrictions in the availability of geographical context variables for all nations of the UK, the sample analysed was for households resident in England at both waves. After dealing with missing values, this constituted 19,334 households.

The dataset limits the study to changes over a 12 month period. However, in relation to the previous studies reviewed in the "Literature review" section, the contribution of the analysis is three-fold: (i) it is based on a far larger sample than previous studies of car ownership change and life events; (ii) it differentiates between different level changes in car ownership; and (iii) the models incorporate detailed measures of the built and social environment.

\section{Analytical approach}

Each car ownership level change type is conditional on being in a particular starting car ownership state in wave one. Thus a two-step regression model structure was applied. In step one, cross-sectional models were estimated for belonging to each of the wave one starting car ownership states: zero car, one car or two cars. In step two, regression models were estimated for the following car ownership level change types: zero to one or more cars, one to two or more cars, two to one or zero car and one to zero car. The level change 
models were estimated on the sub-sample of households with the appropriate number of cars in wave one. The dependent variables for each model are described in Table 1 (this includes three car households for completeness). Note that we confirm Dargay and Hanly's (2007) observation that changes between one and two car (in either direction) are the most frequently observed level change type.

The central focus of our analysis was the car ownership level change models. Unordered or ordered multinomial models have commonly been estimated in cross-sectional studies of car ownership. Potoglou and Susilo (2008) argued that unordered multinomial models are preferable to ordered models when dealing with car ownership as they are more flexible and are found to have greater explanatory power. We estimated binary logistic models but an alternative would have been to employ multinomial logistic models. In our analysis we were interested in quantifying the effect of predictors on a binary outcome. As an example, for the one car starting position a multinomial logistic regression model could have been used to identify predictors of an increase to two or more cars and predictors of a decrease to zero cars against a reference of maintaining one car. We were interested in predictors of an increase to two or more cars against a reference of either decreasing to zero cars or maintaining one car. Hence we used binary logistic models. For consistency, we also used binary logistic models for the wave one car ownership state (i.e. having 0,1 or 2 cars). Here this results in a loss of efficiency in model estimation (compared to using a multinomial logistic model) and in difficulty interpreting coefficients for the intermediate outcome state $(1$ car). Nevertheless, it assists interpretation of the level change models. For example, it allows it to be easily seen what predicts a household having one car compared to any other number of cars and what predicts a one car household increasing their number of cars.

In binary logistic regression models the dependent variable takes the value ' 1 ' for the outcome of interest (being in a particular car ownership state in wave one or undergoing a particular car ownership level change by wave two) or ' 0 ' otherwise. With the logistic model a binomial distribution is assumed for the dependent variable together with a log-

Table 1 Dependent variable descriptive statistics

\begin{tabular}{|c|c|c|c|c|c|c|c|c|c|c|}
\hline \multirow[t]{2}{*}{ Variable } & \multicolumn{2}{|c|}{ Full sample } & \multicolumn{2}{|c|}{ Zero car } & \multicolumn{2}{|c|}{ One car } & \multicolumn{2}{|c|}{ Two car } & \multicolumn{2}{|c|}{ Three car } \\
\hline & $\mathrm{n}$ & $\%$ & $\mathrm{n}$ & $\%$ & $\mathrm{n}$ & $\%$ & $\mathrm{n}$ & $\%$ & $\mathrm{n}$ & $\%$ \\
\hline \multicolumn{11}{|l|}{ Cross-sectional models } \\
\hline 0 Car & 4472 & 23.1 & - & - & - & - & - & - & - & - \\
\hline 1 Car & 8449 & 43.7 & - & - & - & - & - & - & - & - \\
\hline 2 Cars & 5088 & 26.3 & - & - & - & - & - & - & - & - \\
\hline 3 Cars & 1325 & 6.9 & - & - & - & - & - & - & - & - \\
\hline Total & 19,334 & 100.0 & - & - & - & - & - & - & - & - \\
\hline \multicolumn{11}{|c|}{ Car ownership level change models } \\
\hline $\begin{array}{l}\text { Increase car ownership } \\
\text { level }\end{array}$ & 1728 & 8.9 & 463 & 10.4 & 737 & 8.7 & 378 & 7.4 & 150 & 11.3 \\
\hline $\begin{array}{l}\text { Decrease car ownership } \\
\text { level }\end{array}$ & 1751 & 9.1 & 0 & 0.0 & 460 & 5.4 & 768 & 15.1 & 523 & 39.5 \\
\hline No change & 15,855 & 82.0 & 4009 & 89.7 & 7252 & 85.8 & 3942 & 77.5 & 652 & 49.2 \\
\hline Total & 19,334 & 100.0 & 4472 & 100.0 & 8449 & 100.0 & 5088 & 100.0 & 1325 & 100.0 \\
\hline
\end{tabular}


odds link function, which provides the transformation to a linear model. The resulting logistic regression model can be written as:

$$
\operatorname{Prob}(\text { event })=\frac{1}{1+e^{-Z}}
$$

where $Z$ is the linear combination:

$$
Z=\beta_{0}+\beta_{1} X_{1}+\beta_{2} X_{2}+\cdots+\beta_{n} X_{n}
$$

and $\beta_{0}, \beta_{1}, \ldots, \beta_{n}$ are regression coefficients; $X_{0}, X_{1}, \ldots, X_{n}$ are the independent variables.

Baseline variables for household characteristics at wave one are included in the crosssectional models and the level change models. The level change models also include life event variables representing changes in household characteristics between waves one and two. Interactions were tested for life events that were observed from bivariate analysis to tend to coincide. This included moving home and gaining/losing an adult, gaining/losing a partner and gaining/losing an adult, and having children and moving out of employment. The only interaction that was found to be significant was having children and moving out of employment in the two to one car level change model. Non-significant interaction terms were excluded from the preferred models (as their inclusion complicates model interpretation without adding insight).

\section{Using households as the unit of observation in a dynamic framework}

The number of cars owned by a household is strongly influenced by the composition of the household itself, which in many instances is likely to have changed between consecutive years. Consequently, the car ownership level change models should not be interpreted simply as reflecting changes in the number of cars owned by static household units. For instance, consider a model of the one to two car ownership level change. The state change will likely include some one car owning households that have begun cohabiting with another one car owning individual (forming a two car household).

In the sample used in the analysis, where households split into two it has been possible to follow both of the new households into the successive year. The two new households are compared against the original wave one starting position. Where new people have joined existing panel households it is not possible to compare the new household to the starting position of the joiners (as they were not surveyed in wave one). As a consequence there is an over-representation of dividing households which tend to be smaller in size. We control for this as far as possible in the regression models by including dummy variables for increase/decrease in the number of adults and for dividing households. An alternative approach would exclude all households units that changed their composition between the two waves. This removes some important life events relating to household structure. However, we have run this as a sensitivity test as described later in "The one to zero car level change" and "The two to one/zero car level change" sub-sections under "Regression model results".

\section{Explanatory variables: baseline}

Baseline variables include indicators of household structure and life-stage, indicators of households' socio-economic status and indicators of the geographical context in which households reside. The geographical context variables were drawn from other neighbourhood level data sets and linked to UKHLS via a geographic identifier-the UK census 
lower layer super output area (LSOA) in which households reside. These linked variables are summarised in Table 2. Note that spatial context variables are unlikely to change significantly between two consecutive waves. Hence we consider it appropriate to include spatial context measures as baseline variables only. The regression model results tables (Tables $4,5,6)$ report descriptive statistics for all explanatory variables (counts and percentages for categorical variables and means and standard deviations for continuous variables).

\section{Explanatory variables: life events and other change variables}

The selection of change variables for inclusion was guided by our assessment of past research (reviewed in this paper but also more broadly in Clark et al. 2014) and included variables that are commonly found to change, are measurable and are expected to potentially influence transport needs and travel behaviour. We were particularly interested in the role of significant life events (which involve a structural change in circumstances) in the process of car ownership change.

Dummy variables were coded for the range of life events summarised in Table 3. Note that these dummy variables indicate whether any adult member of the household had experienced the life event between wave one and wave two. Changes in employment situation and residential relocations were the most commonly reported, while retirement was the least commonly reported. For each life event subgroup, Table 3 also reports the proportion of households that experienced the different car ownership level changes. Usually the life event makes a change more likely (compared to the sample average), except when this is counterintuitive (gaining a driver licence and cars decreasing). This provides a first indication that different life events are associated with different car ownership level changes. In particular the birth of a child is only associated with the zero to one car and the two to one car ownership level changes.

\section{Regression model results}

The logistic regression model results, presented in Tables 4, 5 and 6, enable us to examine whether the associations between life events and the different car ownership level changes remain after controlling for other explanatory variables.

\section{Cross-sectional models}

We briefly summarise the results of the cross-sectional models first. These confirm that the number of household cars is strongly associated with household size, the life-stage of its members, socio-economic status and residential location type.

Non-car ownership is predicted by being a younger household, not having cohabitating adults, not having children aged 5-11, lower educational and economic status, living in a larger urban area, greater access to local services and buses and higher level of deprivation.

Two car owning households are predicted by being an older household (but not 75 years or older), having cohabitating adults, having children aged 5-11, higher educational and economic status, not living in a larger urban area, lack of access to local services and rail station and lower level of deprivation. 


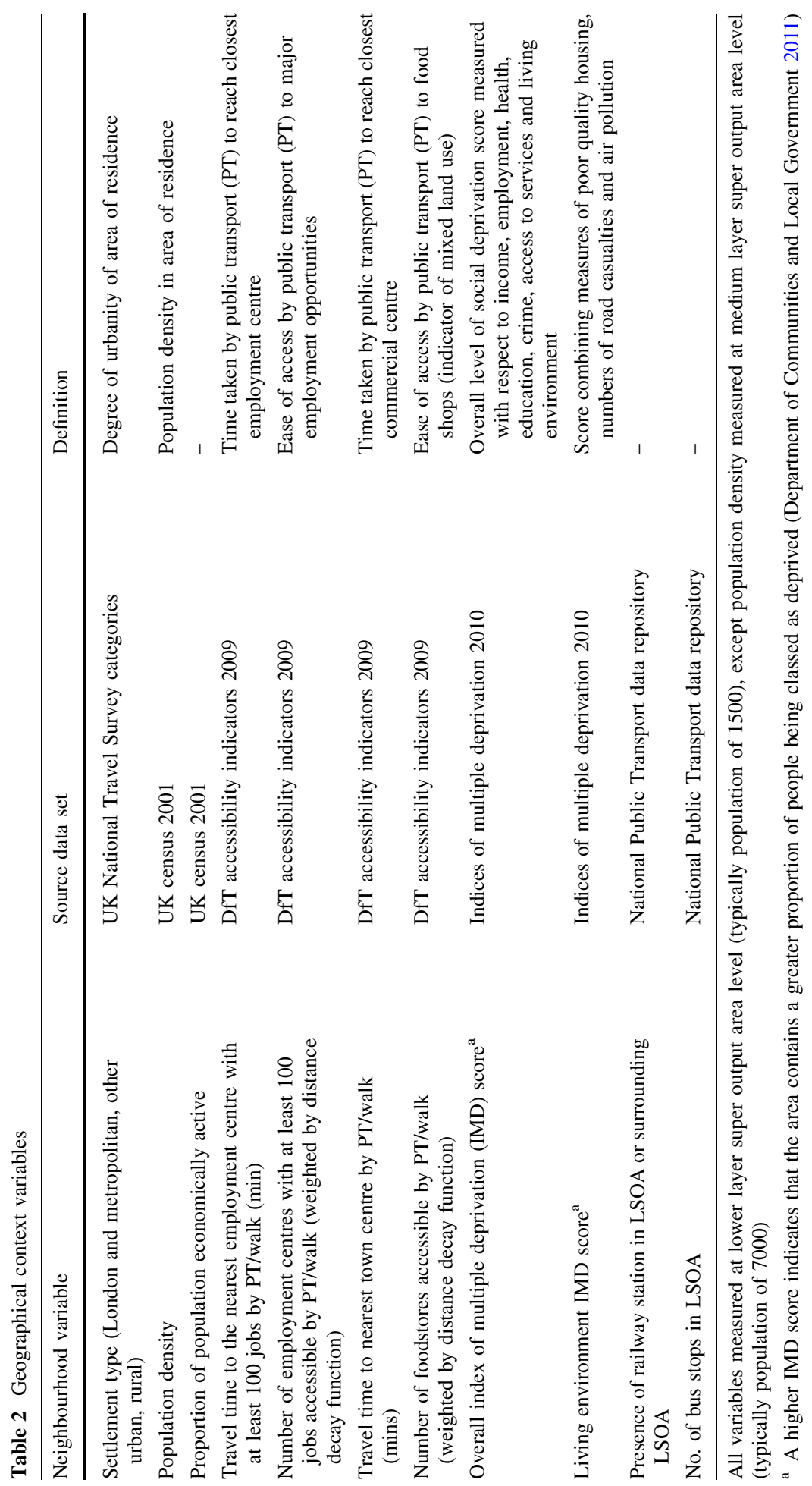




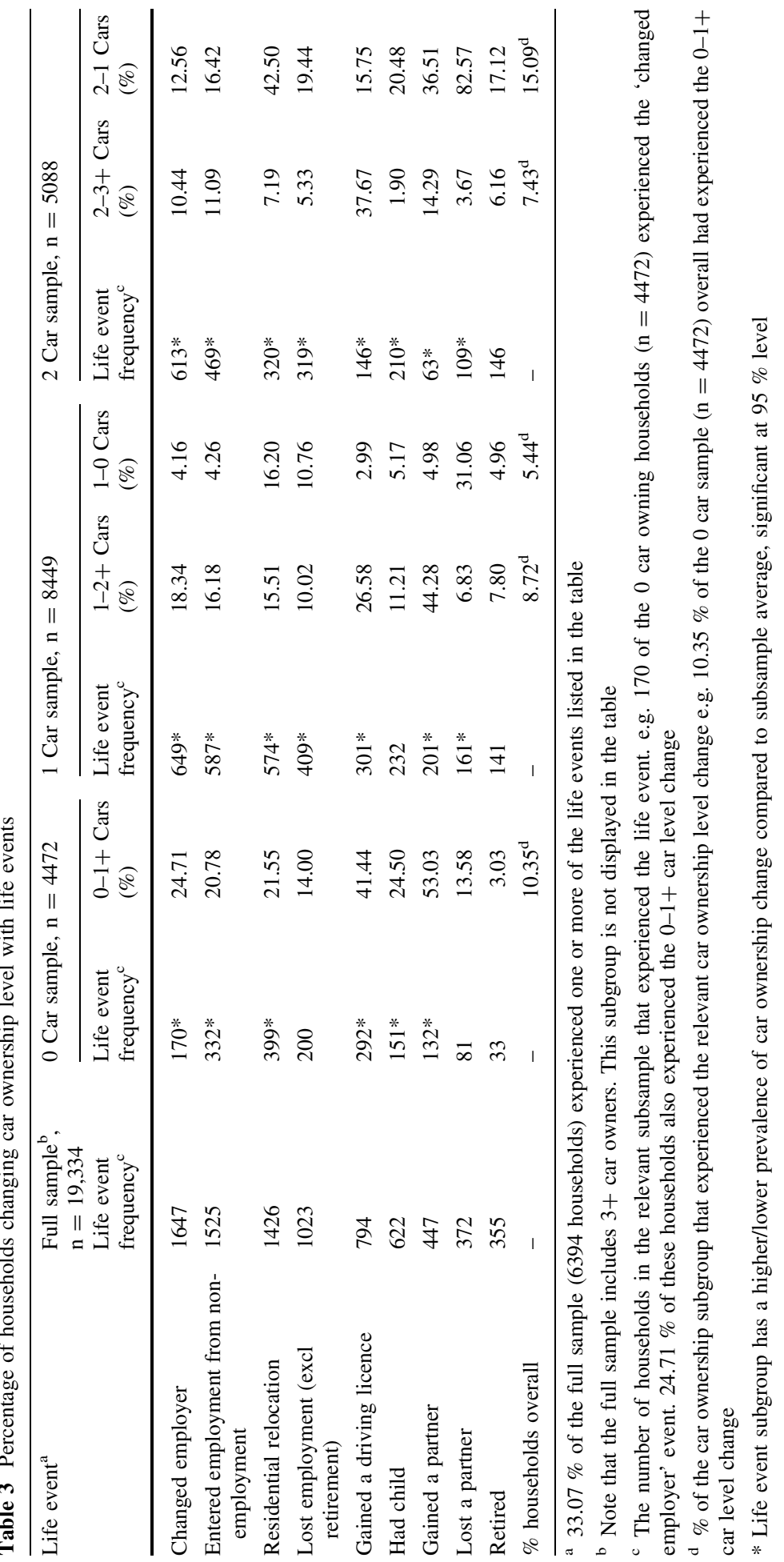




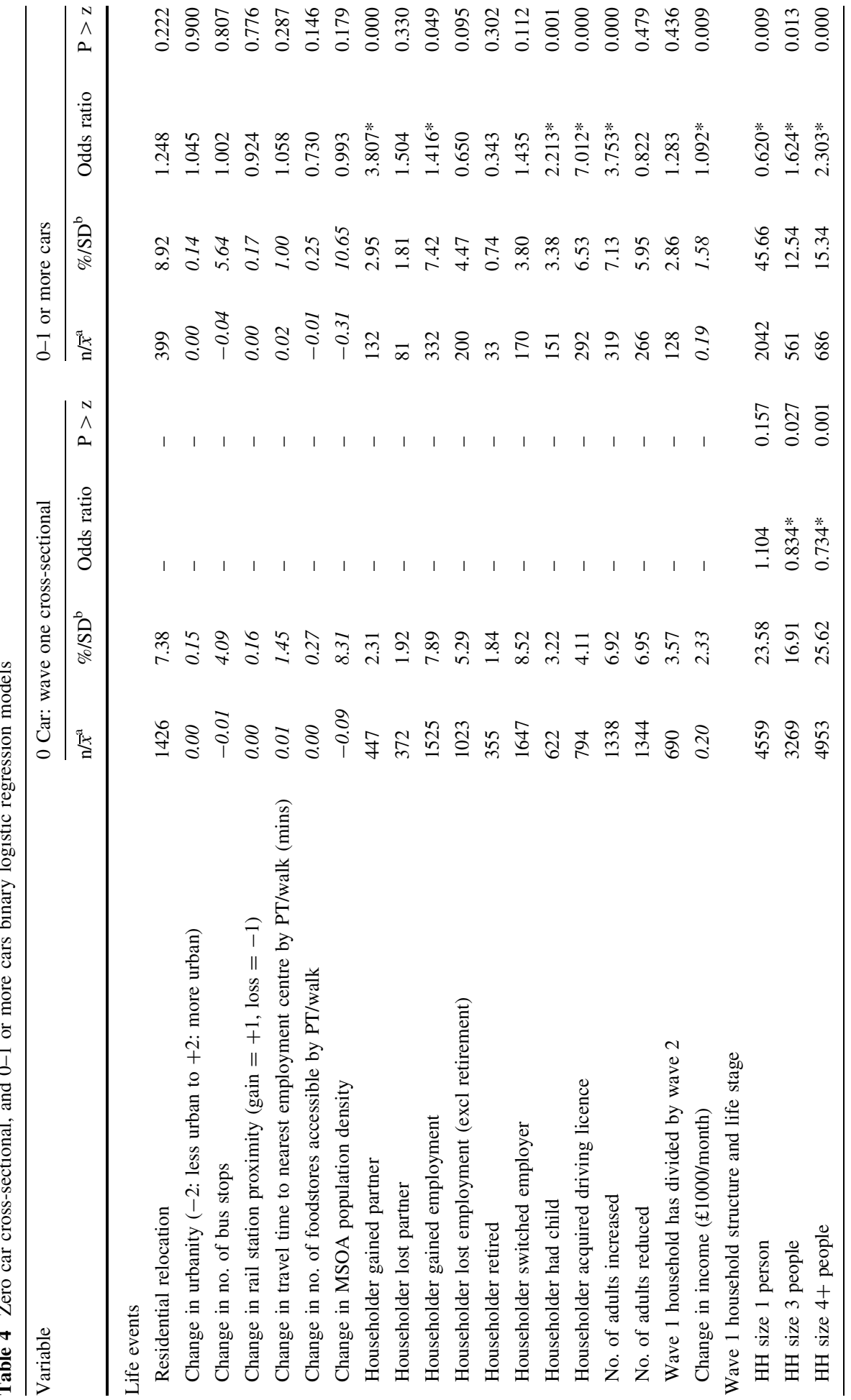




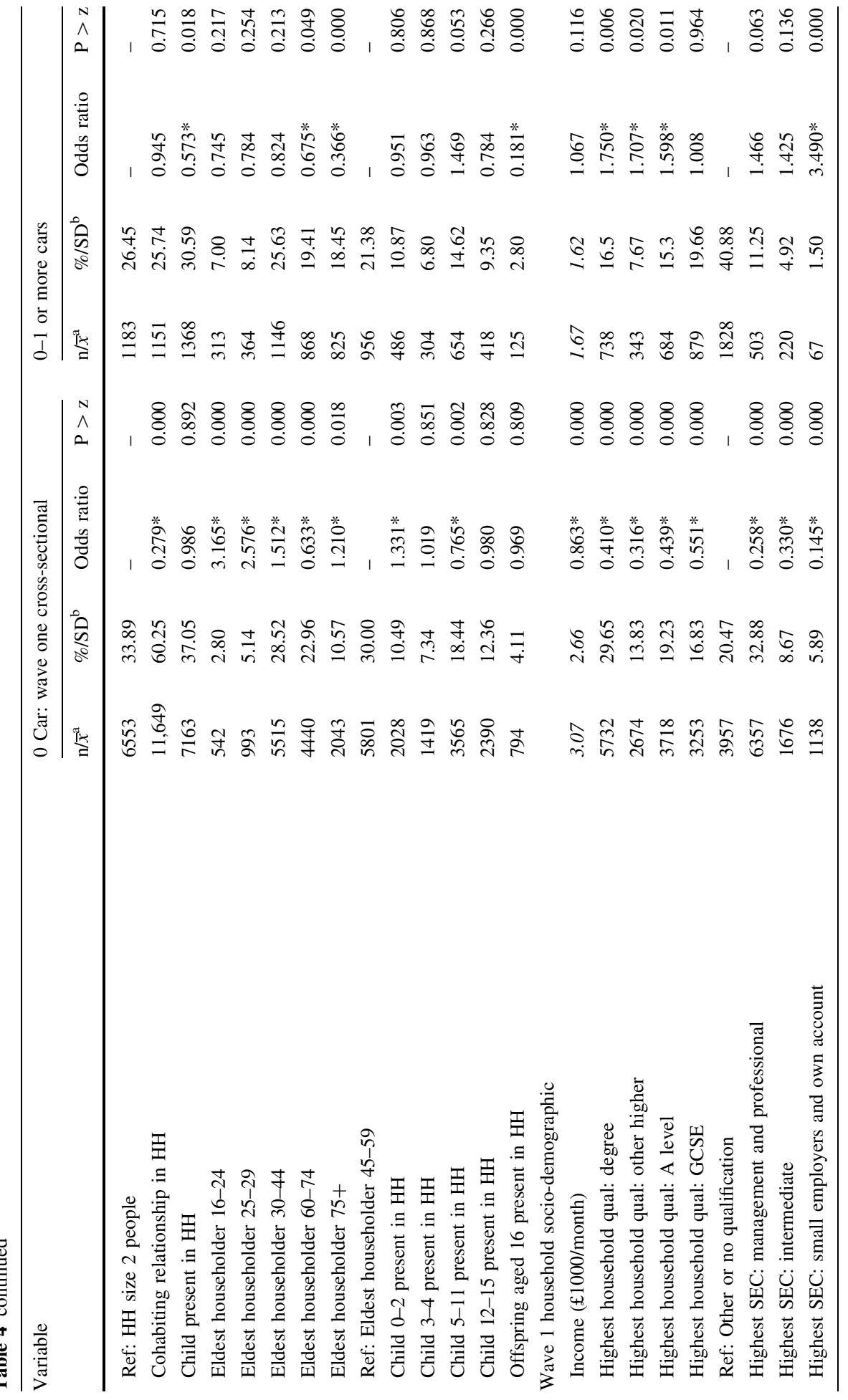




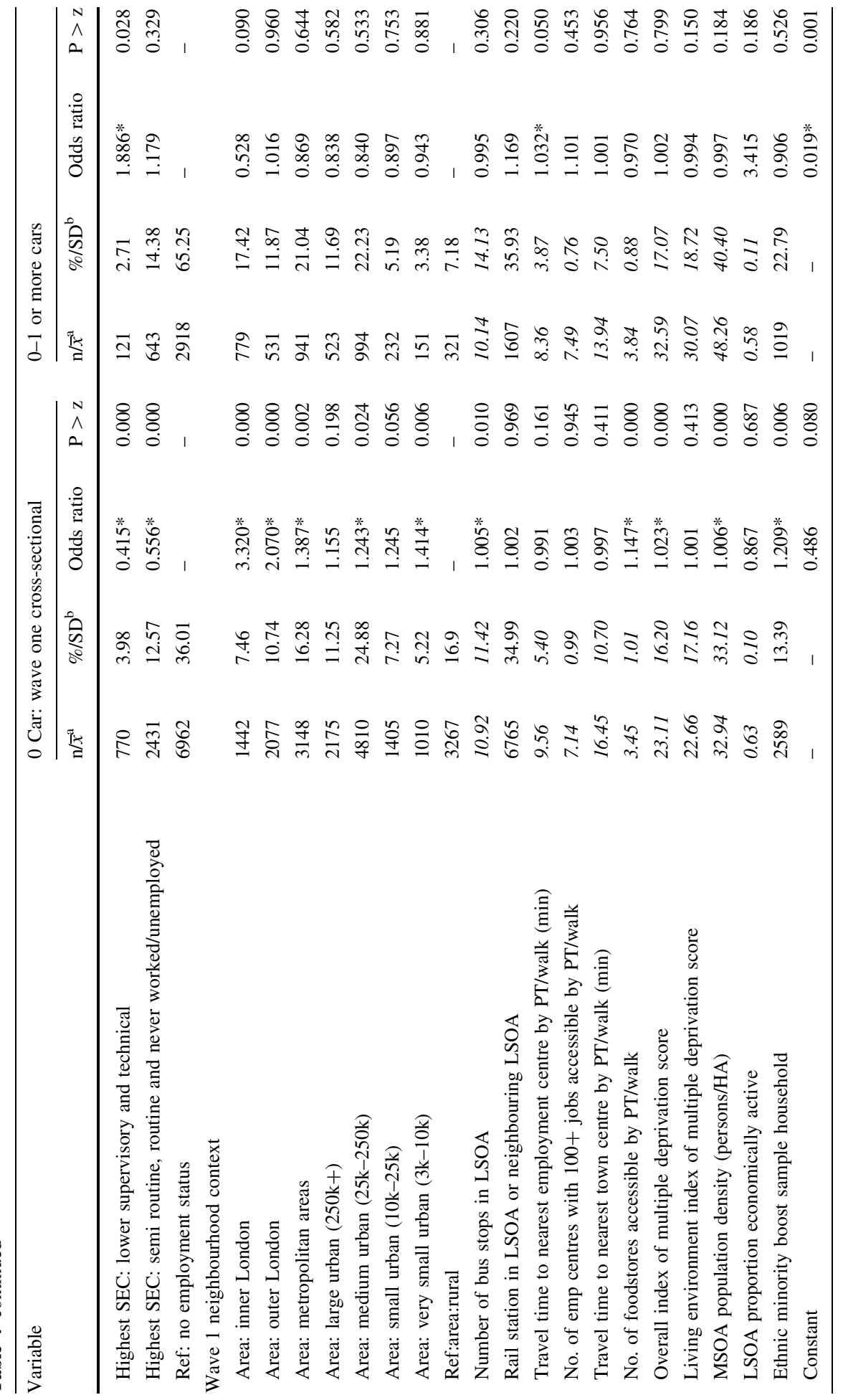




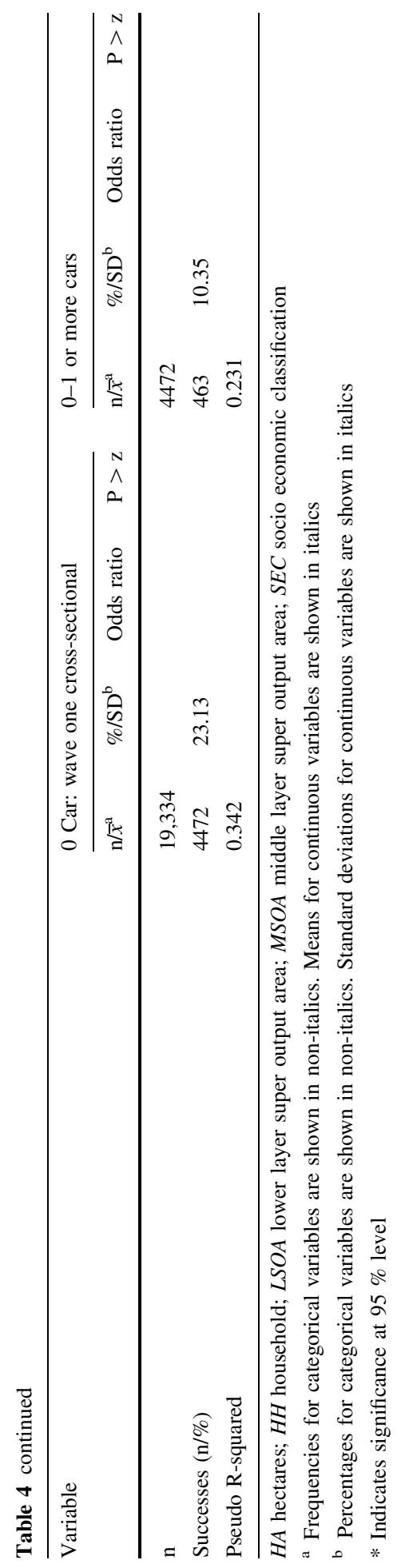




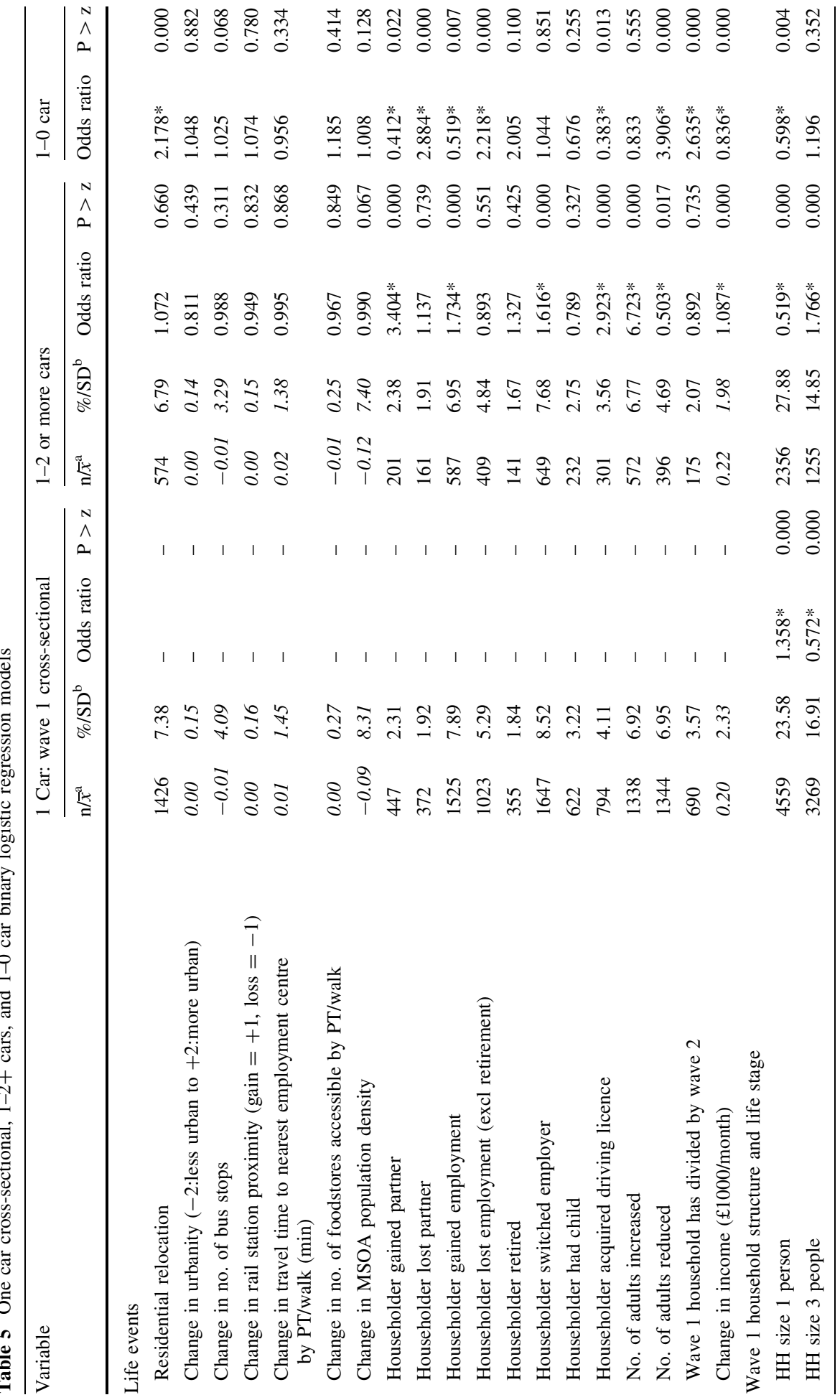




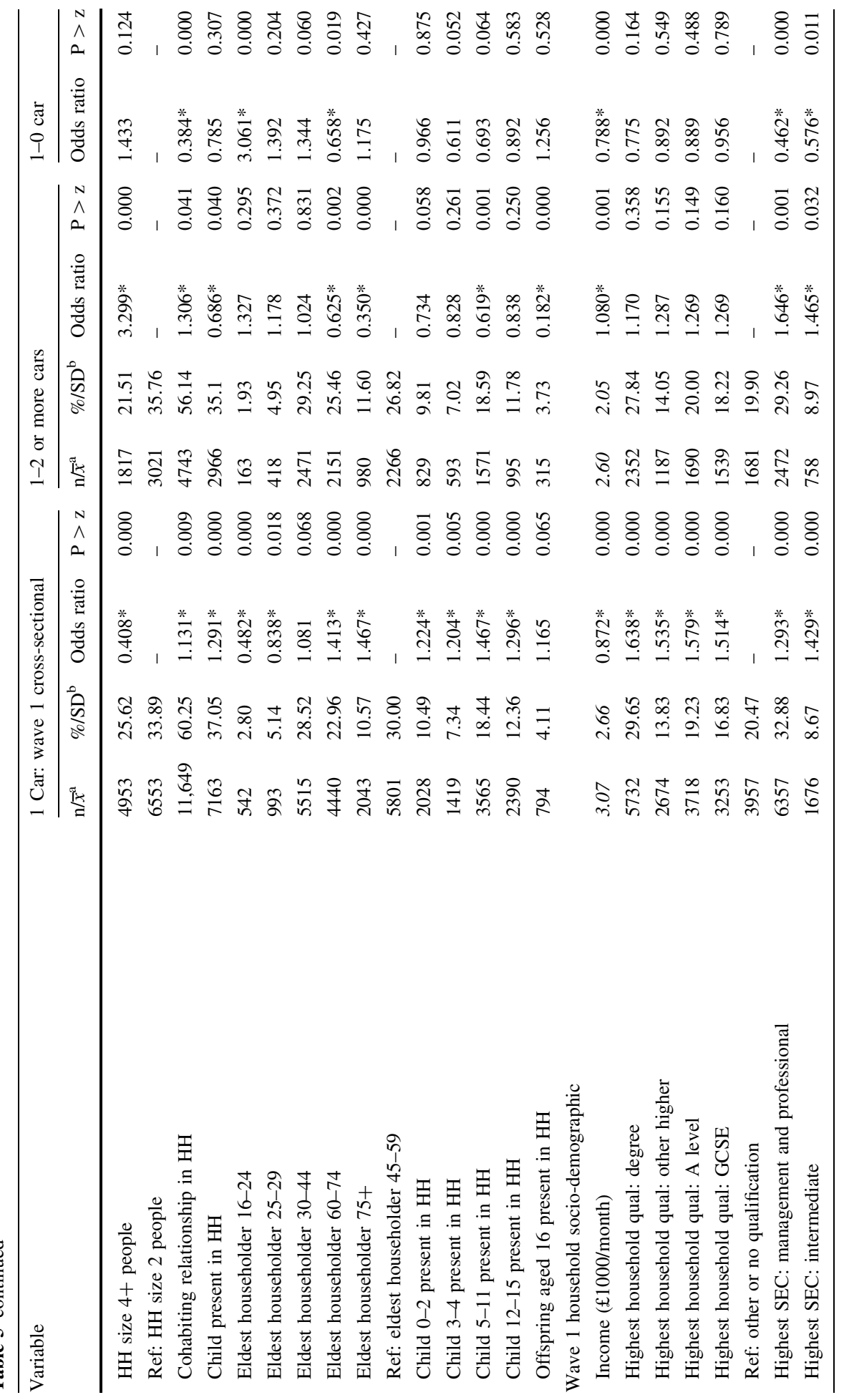




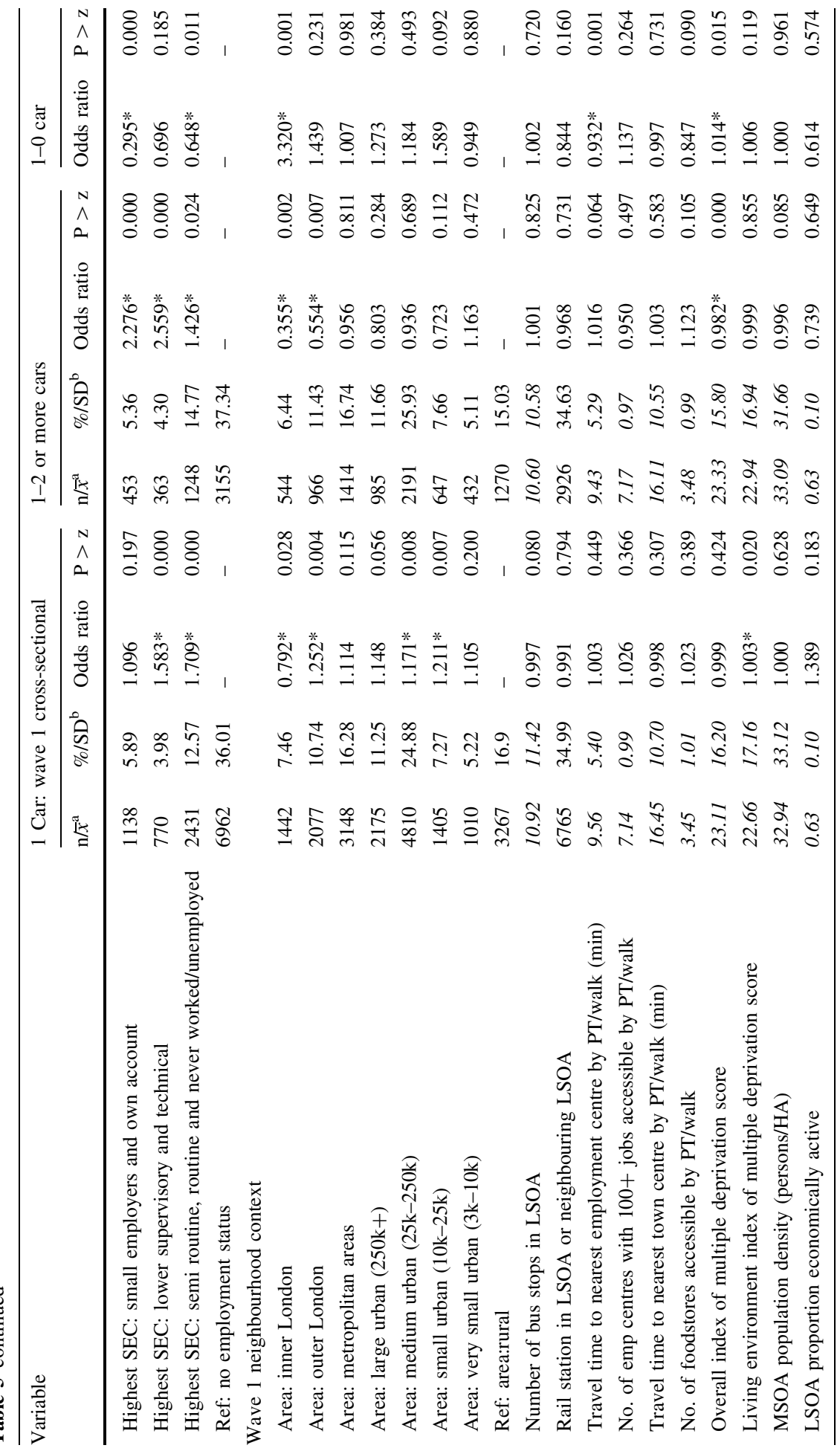




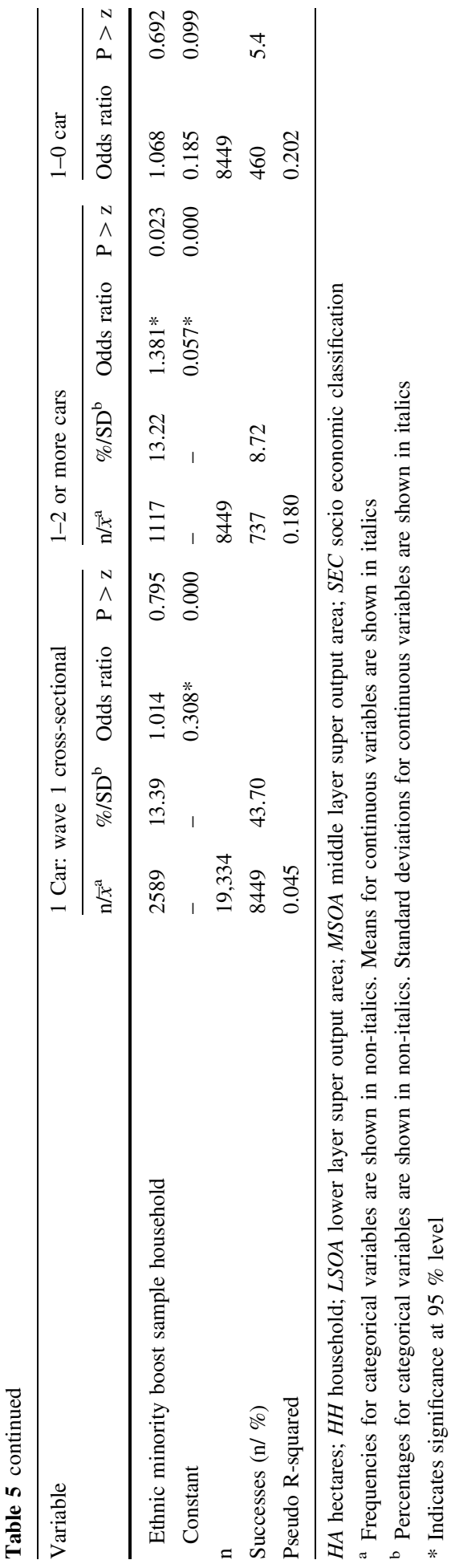




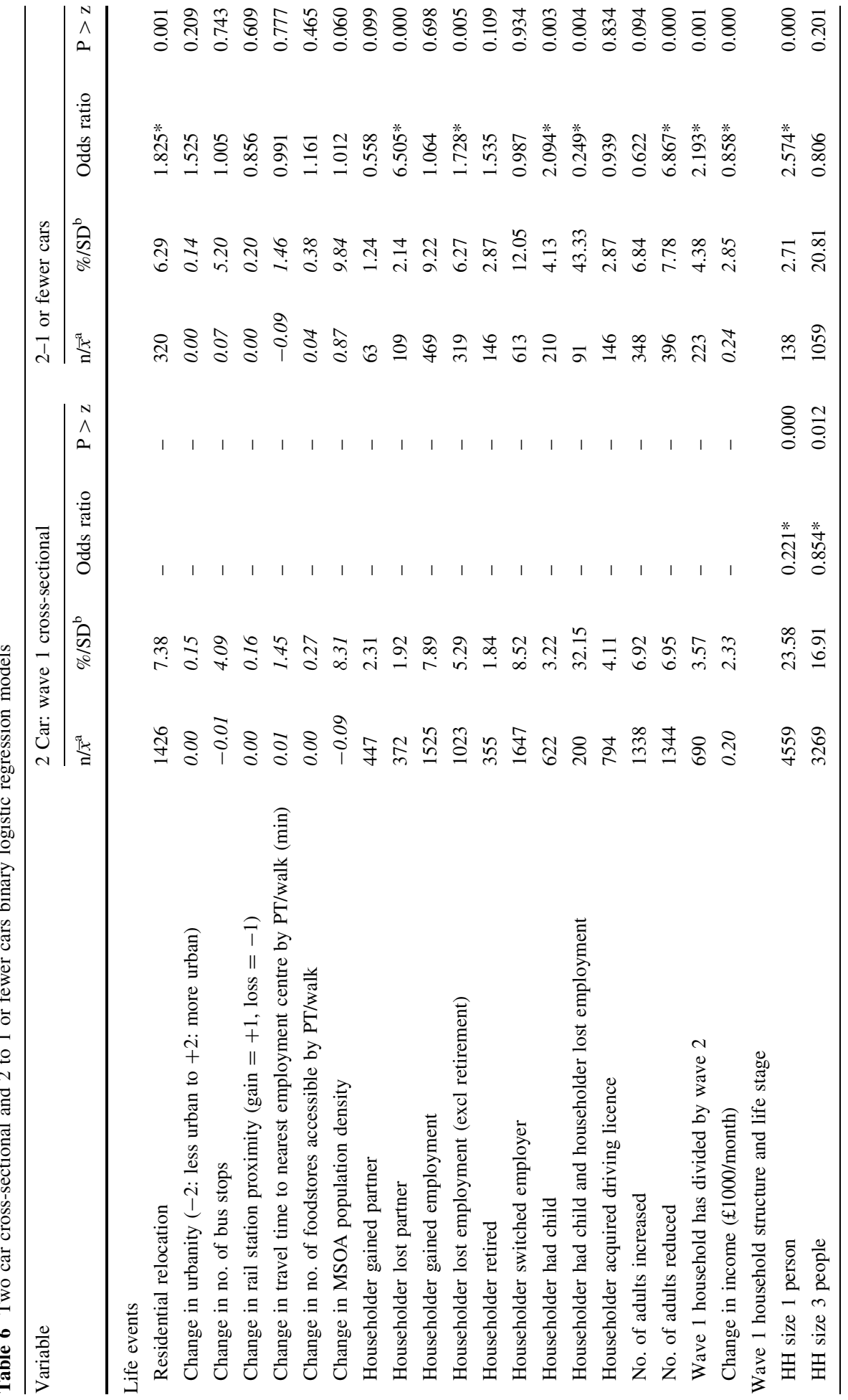




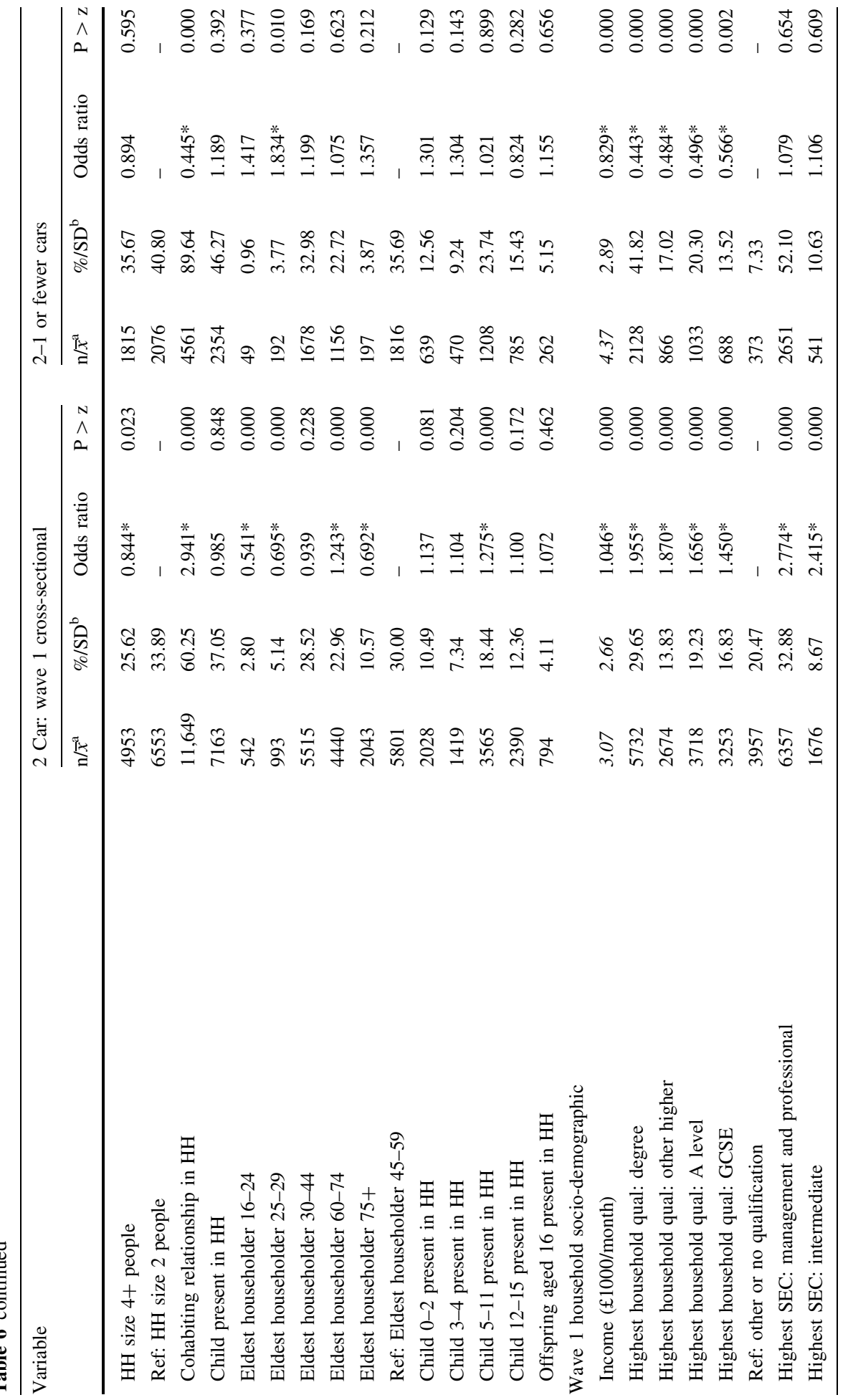












The one car owning state occurs across a broader range of circumstances although notably is predicted by being a single adult household, having children present and being an older household (aged 60 years and above).

These results are consistent with the notion of the household car ownership life-cycle but show also that socio-economic and spatial circumstances matter. There is also substantial unexplained variation in the models, indicating that car ownership varies among similar households and lifestyles and attitudes play a role. The level change models that follow identify the factors that increase the likelihood of changing from these starting car ownership states.

The zero to one car level change

\section{Baseline conditions}

Non-car ownership is generally associated with smaller household units and it is the larger non-car owning households that are most likely to gain a car. Older non-car owning households (aged 60+) are the least likely to acquire a car. Households with children present are also less likely to acquire a car than those without children, except when they have children of 5-11 years of age. This is consistent with the cross-sectional model for 0 cars which found that having children of 5-11 years of age reduced likelihood of being a non-car owner.

Acquiring a car is also more likely amongst more highly educated households, although household income in the base year is not significant. With respect to employment type, those working for small employers or in self-employment and those in lower supervisory and technical occupations are more likely to acquire a car-this suggests that these employees have greater need for car based mobility. While long journey times to employment centres by public transport are found to increase the likelihood of acquiring a first car, settlement type does not. This implies that non-car owners tend to self-select into urban areas that satisfy their mobility needs, but it is other factors that govern whether they gain a first car or not.

\section{Life events}

The acquisition of a driving licence most strongly increases the likelihood of a household acquiring a first car, emphasising that driving licence acquisition involves a strong commitment to immediate car ownership. This is followed by events associated with changes in household composition. As expected, an increase in the number of adults in the household strongly increases the likelihood of a household gaining a car. After controlling for this, gaining a partner is associated with a large increase in likelihood of acquiring a car (see the "Summary and implications for research and policy" section for discussion of this). Having a child increases the likelihood of acquiring a car, indicating that becoming a parent provides an impetus to become a car owner, although it has been explained that those households who already had children were less likely than other households to acquire a car. This suggests that households act at the time of having children to acquire a car where they do not have one. Moving into employment and an increase in household income also increase the likelihood of acquiring a car.

Although there is a bivariate association between residential relocations and acquiring a first car, residential relocations and changes in settlement type/accessibility are not significant after controlling for other factors. Given that base year settlement type also has no 
effect, it would appear that life-cycle events associated with household composition changes (cohabitation, child birth) and employment are more fundamental drivers for changes from zero to one car.

The one to zero car level change

\section{Baseline conditions}

Being very young (16-24) and residing in inner London are strongly associated with the one to zero car level change. Car ownership in very early adulthood can be expected to be volatile due to lower earning potential, for example. Being located in inner London provides far greater access to multi-directional public transport compared to anywhere else in the UK, thus reducing the need to own a car. Consistent with this is the finding that long journey times to employment centres by public transport reduce the likelihood of becoming car free.

In line with expectations, having a low income and low employment status are associated with increased likelihood of moving into non car ownership. After controlling for income, living in an area of higher deprivation increases the likelihood of relinquishing a vehicle.

\section{Life events}

Moving to a non-car owning state is most strongly associated with changes in household composition. Losing an adult increases the odds of losing a car by a factor of nearly four. After controlling for this, losing a partner remains significant. In the opposite direction, gaining a partner reduces the likelihood of relinquishing an only car.

Moving out of employment is associated with increased likelihood of relinquishing a car, while gaining employment reduces the likelihood. Separately, it is found that a decrease in household income increases the likelihood that a car will be relinquished.

Lastly, moving to a car free state is associated with residential relocations, which increase the odds of relinquishing a car by a factor of 2.18. Note this effect remains after removing dividing households from the sample. There is only a weak effect of the type of move made. Moving to an area with a higher number of bus stops is associated with increased likelihood of becoming car free (significant at the $90 \%$ level). The increased likelihood of relinquishing a car for those moving house (regardless of the nature of the change in built environment and independent of other life events) suggests that home moves are taken as opportunities to review car ownership needs.

The one to two car level change

\section{Baseline conditions}

Single-car ownership is generally associated with smaller household units and it is the larger one-car owning households and those with cohabitees that are most likely to gain a second car. With respect to life-stage, households in all age categories between 16 and 59 years are equally likely to gain the second car, while households over 59 are less likely to acquire a further car. Presence of children reduces the likelihood of gaining a second car with the effect largest for those households with children aged 5-11 or aged 16 or above. 
Higher income is associated with increased likelihood of gaining a second car. Qualification level is not significant (but is for the zero to one car level change, indicating different motivations for acquiring the first and second car). Being in employment increases the likelihood of acquiring a second car.

Living in London reduces the odds of acquiring a second car. Long journey times to employment centres by public transport and lower population densities increase the likelihood of acquiring a second car (significant at the $90 \%$ level). Higher deprivation in the neighbourhood reduces the odds of acquiring a second car.

\section{Life events}

Increasing the number of adults in the household strongly increases the likelihood of a household gaining a second car. After controlling for this, gaining a partner remains significant. Acquiring a driving licence has the next strongest effect, re-affirming that driving licence acquisition demonstrates a strong commitment to car ownership.

In this case, both moving into employment and changing employer are associated with increased likelihood of gaining a second car. It is unclear why an employer switch might encourage acquisition of an additional car. It might tend to involve changes in employment location relative to the home which increase the need for car travel or might involve increased mobility requirements as part of the new employment role. Alternatively, it is conceivable that the acquisition of a second car enables the employment change (so the relationship between employment and car ownership operates in the other direction). Again an increase in household income is found to make it more likely that an additional car will be acquired.

Residential relocations are not significant. However, moving to an area with higher population density is weakly associated with reduced likelihood of gaining a second car (significant at the $90 \%$ level).

The two to one/zero car level change

\section{Baseline conditions}

While cohabitation reduces the likelihood of losing the second car, it is the small number of single occupancy households with two cars (138) that are the most likely to relinquish a vehicle. Being an early life-stage two car owning household (aged 25-29) increases the likelihood of losing the second car. This could indicate general increased life volatility during this period. The model also confirms that higher levels of education and higher income reduce the likelihood of losing the second car, while employment type has no effect.

With respect to urban form, a London effect is once again apparent_-London dwelling two car owners are more likely to relinquish the second car than households living in other settlement types. A counter-intuitive finding is that long journey times to employment centres by public transport increase the odds of losing the second car. Living in an area of higher deprivation increases the odds of losing a second car.

\section{Life events}

Losing an adult increases the odds of losing a car by a factor of nearly seven. Again after controlling for this, losing a partner remains significant. Having a child is found to increase 
the likelihood of relinquishing a car, as is having a household member moving out of employment. The interaction between having a child and losing employment was tested and found to be significant. Including this term increased the significance of the independent 'had child' and 'lost employment' events, but introduces complexity in model interpretation. Instances of having a child that are not associated with employment changes increase the likelihood of losing the second car. This will apply to circumstances in which one parent is already not working and the birth of a child prompts a car relinquishment (perhaps as a result of changing activity patterns or expected expenditure). Instances of employment losses that are not associated with having a child also increase the likelihood of losing the second car. However, the combined effect of having a child at the same time as moving out of employment (which for the majority of cases relates to maternity leave) does not significantly change the likelihood of losing a second car. This might suggest that the second car is initially retained in circumstances in which the change in employment (with childbirth) is known to be temporary. Overall we can say that active employment status is associated with increased tendency to own a second car. Again, an increase in household income is associated with reduced likelihood of relinquishing a car.

As with the case of relinquishing a car for one car households, residential relocations are found to increase the likelihood of relinquishing the second car. However, a sensitivity test indicated that residential relocations lose significance if dividing households are excluded from the sample. Dividing households have a tendency to become smaller in size and whilst changes in household size are controlled for in the reported model, there appear to be unobserved characteristics of these households that increase the likelihood of relinquishing the second car at the time of a move. A weak effect of changes in urban form is detected. Increasing population density (a proxy for greater accessibility) increases the odds of losing the second car.

\section{Predicted probabilities for illustrative cases}

To illustrate the effect of the life event relationships the models have been used to predict probabilities of car ownership level changes occurring for eight stylised households (Table 7). The stylised households are typical of those observed in the sample as being in the required car ownership state in wave one and to have experienced the different life event-car ownership level change combinations by wave two.

A first observation is that the probability of any car ownership level change occurring in the absence of a life event is quite low for the cases tested. With respect to increases in car ownership, the highest increase in probability is associated with an increase in household size following partnership formation. For example, the probability of case one-a car free single occupancy household-gaining a car increases from 4 to $34 \%$ in association with partnership formation. Employment changes and child birth have quite modest impacts by comparison.

With respect to decreases in car ownership, the predicted probabilities illustrate that the one to zero car level change is highly unlikely for a mid-aged household. Consequently, even a doubling of the odds following the loss of a partner means that the loss of the only car remains unlikely (a $4 \%$ chance for case eight). This is in contrast to the two to one car level change which is far more likely: losing a partner increases the probability of this level change occurring from 7 to $32 \%$. This is accentuated if a household member also relocates (increasing the probability to $46 \%$, see case seven). The birth of a child has a moderate impact if it occurs independently of employment changes, increasing the probability of relinquishing the second car from 9 to $17 \%$. 


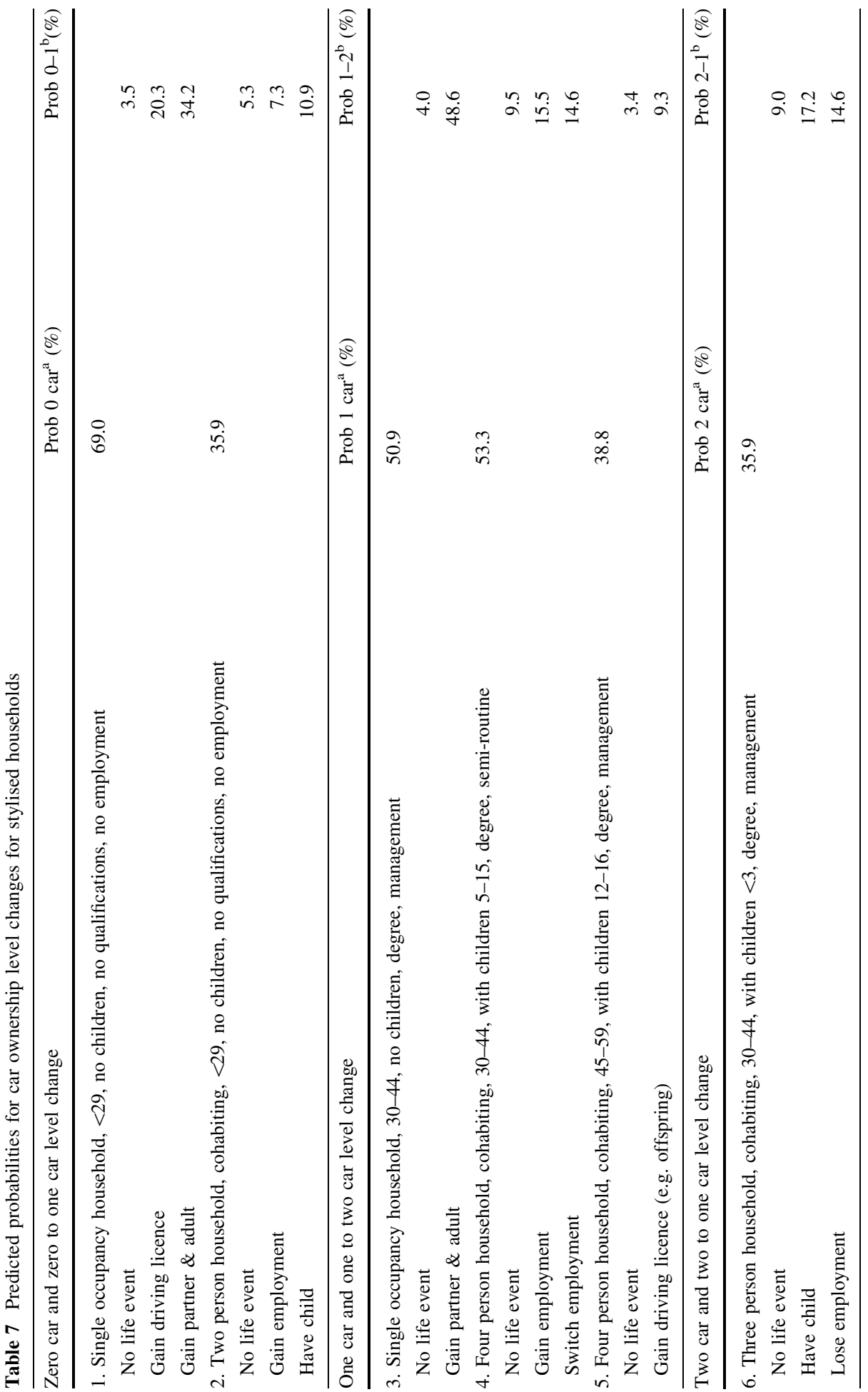




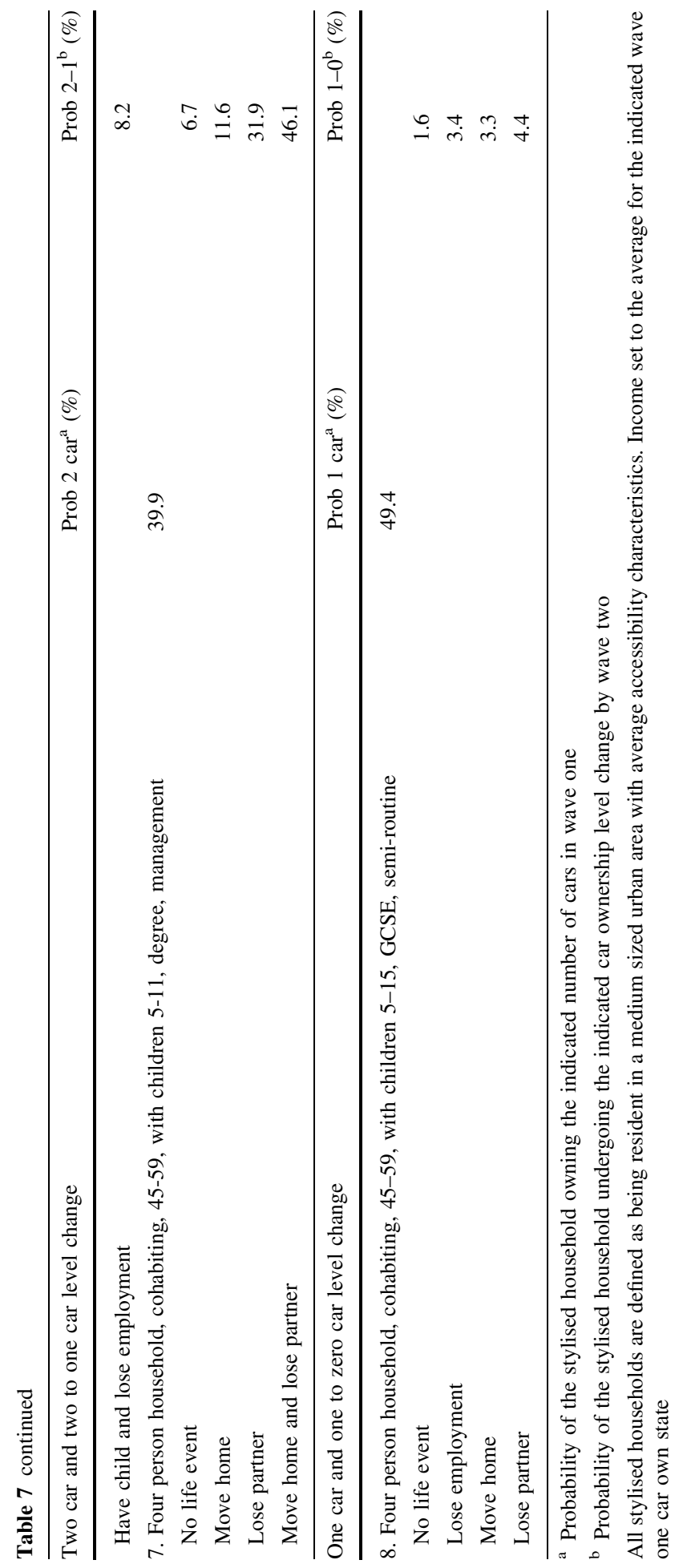




\section{Summary and implications for research and policy}

The relationships between life events and the different types of car ownership level change are summarised in Table 8.

The paper now synthesizes the implications of the findings for travel behaviour research and for policy and practice and provides recommendations for further research.

Theoretical insights

On the whole the results are consistent with the life-cycle conceptualisation presented in Fig. 2-car ownership is strongly influenced by household composition which in turn is related to life-stage. However, the models also indicate that younger households (16-29) are the most likely age group to experience vehicle relinquishments (1-0 and 2-1 cars), possibly as a consequence of greater life volatility in early adulthood. Thus the life-cycle effect can only be considered to be a general tendency and not a normative experience. It is also acknowledged that there is heterogeneity in household car ownership within life-stage groups which is not explained in the models. For example, while $85 \%$ of mid-aged (45-59) households with children in the sample own at least one car, $15 \%$ of these households do not own a car. The variation here is partly explained by socio-economics (e.g. income) and spatial context (e.g. settlement type) but the model fits (e.g. pseudo $\mathrm{R}^{2}$ value of 0.34 for the zero car model) imply that there are other factors that play a role-for instance life-style preferences or attitudes.

Table 8 Relationships between life events and car ownership level changes

\begin{tabular}{|c|c|c|c|c|}
\hline Life event & $0-1$ car & $1-2$ car & $2-1$ car & $1-0$ car \\
\hline \multicolumn{5}{|l|}{ Family biography } \\
\hline Gain an adult & ++ & +++ & $-{ }^{\mathrm{a}}$ & \\
\hline Lose an adult & & & +++ & ++ \\
\hline Gain partner & ++ & ++ & & - \\
\hline Lose partner & & & +++ & ++ \\
\hline Had child & ++ & & ++ & \\
\hline Acquired driving licence & +++ & ++ & & - \\
\hline \multicolumn{5}{|l|}{ Residential biography } \\
\hline Residential relocation & & & + & ++ \\
\hline Increase in number of bus stops & & & & $+^{\mathrm{a}}$ \\
\hline Increase in pop dens & & $-^{\mathrm{a}}$ & $+^{\mathrm{a}}$ & \\
\hline \multicolumn{5}{|l|}{ Employment biography } \\
\hline Gain employment & + & + & & - \\
\hline Switch employer & & + & & \\
\hline Lose employment & & & + & ++ \\
\hline Retire & & & & $++^{\mathrm{a}}$ \\
\hline
\end{tabular}

- Reduces odds; + increases odds and odds ratio $<2$

++ Increases odds and odds ratio between 2 and $5 ;+++$ increases odds and odds ratio $>5$

a indicates significant at $90 \%$ level compared to $95 \%$ level for all other relationships 
Life events and car ownership level changes

It has been observed that partnership formation/dissolution events remain significant after controlling for changes in the number of adults in the household. Closer inspection confirms that cohabitation events tend to be associated with higher likelihood of vehicle gains/ losses compared to other adult increase/decrease events. For example, cohabitation is found to be associated with acquiring a second car in $44 \%$ of cases compared to only $20 \%$ of cases when an adult joins the household for other reasons. These results suggest that adults bring and take cars with them as partnerships form and dissolve and that cars are considered necessary for each partner, rather than being shared (at least in the short term observed with our data).

Driving licence acquisition (which tends to occur before the age of 30) is strongly associated with car acquisition (in the same year), regardless of the number of cars already available in the household. This suggests that those acquiring licences in the household are committed to having their own car, rather than sharing existing household cars.

Gains in employment are associated with increases in car ownership level (zero to one and one to two cars) and losses of employment are associated with decreases in car ownership level (one to zero and two to one cars). A change in employer moderately increases the likelihood of the one to two car transition. Without being able to consider the nature of the employment location or role change, this suggests that employment location/ role changes have the tendency to introduce the need for more car mobility. Alternatively, the relationship between car ownership and employment may operate in the opposite direction, i.e. acquiring an additional car enables an employment change by opening up access to new employment opportunities. It was also found that poorer accessibility to employment by public transport plays a conditional role by increasing the odds of gaining a first car and reducing the odds of losing a first car.

From a policy standpoint, this supports the case for investment in public transport links to employment sites as a means of suppressing growth in car ownership. Employment sites have become increasingly dispersed and newer, urban fringe locations are rarely well served by public transport in the UK. The observation made elsewhere that young adults are now tending to delay acquisition of the driving licence (Levine and Polak 2014) also suggests that there is potential for this cohort to maintain less car dependent life-styles compared to older generations - our results confirm that delaying driver licence acquisition will delay car acquisition and hence car use. Transport policies which facilitate access to key destinations (higher education, employment) for young people have potential to reduce car ownership and use over the longer term.

After controlling for changes in employment, the models indicate that changes to household income also have a strong independent effect in the expected directions. However, in contrast to earlier studies of income and car ownership (Dargay 2001) the model odds ratios imply that reductions in income had a stronger effect on the likelihood of vehicle losses than equal but opposite increases in income had on the likelihood of vehicle gains - for example losing $£ 1000$ per month increases the odds of losing the first car by a factor of 1.19 while gaining $£ 1000$ per month increases the odds of gaining a first car by a smaller factor of 1.09. This income relationship suggests that households were inclined to economise in 2010/11, and this could be a period effect relating to the economic recession of the time. It is certainly worthy of further attention as additional UKHLS waves become available.

Consistent with earlier studies (Dargay and Hanly 2007), second car ownership appears to be more volatile than first car ownership. This supports the notion that second cars may 
have greater sensitivity to policy measures or marketing messages. Indeed, the 'your second car' marketing campaign for local bus transport (Sheffield, UK) has sought to exploit this (Sheffield Bus Partnership 2013). Likewise, City Car Club (UK) seek to market their service as a cost effective alternative to under-utilised second cars (City Car Club 2014).

The birth of a child, amongst those that do not yet own a car, prompts the acquisition of a car. But for some two car owners, child birth prompts the immediate relinquishment of the second car. Case studies from qualitative research have indicated that this transition can take several years (Clark 2012) following a process of adaptation to the parental role, changes in resources and activity patterns. To explain these contrasting findings, the longer term car ownership behaviour of two car owning households that go on to have children would benefit from a specific examination in its own right.

Residential relocations have weaker effects and are only significant in the models that predict reductions in car ownership level. This implies that car ownership increases that coincide with residential relocations are predominantly driven by household composition and employment status changes rather than changes in spatial location. Weak effects of changes in urban form are apparent in the level change models and are in the expected direction i.e. moves that increase local accessibility are associated with reductions in car ownership level. However it is notable that home moves that may substantially change access to transport outside of the home, i.e. between different settlement types (rural to London for instance), were rare in the survey sample.

Overall, the transition models imply that car ownership level changes are more strongly associated with familial events and employment than changes in urban form, at least in the short term. These events may nevertheless influence the residential location choice which contributes to the stronger cross-sectional urban form relationships. Clearly attitudes will also play an important role in car ownership and residential location decisions, but are themselves a dynamic construct being related to life-stage, and past experience of different residential location types. It is unclear, moreover, how to construct a meaningful measure of 'attitude' at the household level.

\section{Implications for dynamic modelling and forecasting}

Forecasts from car ownership models play an important role in supporting transport and land use policy formation and decision making (Feldman et al. 2007). Some researchers advocate the use of dynamic agent-based micro-simulation models to forecast how the population, car ownership and travel behaviour will evolve over time and respond to policy interventions (Salvini and Miller 2005). Agent-based approaches model individual decision makers and predict how their car ownership state evolves in response to changes in their lives and/or the external context. In this respect, the life event relationships with different car ownership level changes, as summarised in Table 8, offer the basis for the development of agent-based micro-simulation car ownership models.

\section{Further research}

Future studies could build on the findings reported here by the use of structural equation modelling (SEM) based path analysis to improve the representation of inter-relationships between life events and car ownership level changes, accounting for direct and indirect relationships (for an example, see Scheiner and Holz-Rau 2013). 
To complement quantitative longitudinal analyses, we also advocate the use of qualitative retrospective life-history methods to deepen understanding of complex interrelationships. For instance, this study has revealed that child birth may result in the relinquishment of a second car for some household types. Improved understanding of this specific case could be gained by employing life history interviews on a small sample of households that are considered to exemplify different circumstances. While qualitative approaches may not provide generalizable evidence, they can reveal the mechanisms that lead to different car ownership states and this can inform further research.

\section{Concluding remarks}

Previous studies of the relationship between life events and car ownership level change have had to rely on comparatively small panel or retrospective data sets. As a consequence, it has not been possible to distinguish between different types of car ownership increases and decreases. This study has demonstrated the value of the larger scale UKHLS which has enabled the generation of a much more comprehensive set of life event and spatial variables, and allowed a detailed examination of the factors associated with different car ownership level changes. A unique contribution is to have established that different life events are associated with different types of car ownership level change. The new panel data also challenges conventional understanding that households are generally reluctant to relinquish vehicles in association with income reductions. We observed that car ownership amongst English households was more sensitive to income reductions in 2010/11 than it was to income increases.

Overall, the results presented in this study offer firm evidence that life events play an important role in travel behaviour change. Life events should therefore be considered in both conceptualisations of travel behaviour change and in policy interventions concerned with facilitating behaviour change.

Acknowledgments The research was supported by the Economic and Social Research Council under the Secondary Data Analysis Initiative (Grant Number ES/K00445X/1). It was conducted in partnership with the Institute for Social and Economic Research, University of Essex (with thanks to Professor Heather Laurie and Dr. Gundi Knies) and the UK Department for Transport (with thanks to Deirdre O'Reilly, Ben Savage, Tom Gerlach, John Screeton, Louise Taylor and Samuel Omolade).

Open Access This article is distributed under the terms of the Creative Commons Attribution License which permits any use, distribution, and reproduction in any medium, provided the original author(s) and the source are credited.

\section{References}

Anowar, S., Eluru, E., Miranda-Morena, L.: Alternative modeling approaches used for examining automobile ownership: a comprehensive review. Transp. Rev. 34(4), 441-473 (2014)

Beaumont, J.: Households and Families-Social Trends 41. Office for National Statistics, London (2011)

Chatterjee, K., Sherwin, H., Jain, J.: Triggers for changes in cycling: the role of life events and modifications to the external environment. J. Transp. Geogr. 30, 183-193 (2013)

City Car Club (2014) Is City Car Club for me. City Car Club. http://www.citycarclub.co.uk/about/is-it-forme. Accessed 24 April 2014

Clark, B.: Understanding how household car ownership changes over time. $\mathrm{PhD}$ thesis, University of the West of England (2012)

Clark, B., Chatterjee, K., Melia, S., Knies, G., Laurie, H.: Life events and travel behaviour: exploring the inter-relationship using the UK household longitudinal study. Transp. Res. Rec. 2413, 54-64 (2014) 
Dargay, J.: The effect of income on car ownership: evidence of asymmetry. Transp. Res. A. 35, 807-821 (2001)

Dargay, J., Hanly, M.: Volatility of car ownership, commuting mode and time in the UK. Transp. Res. A. 41(1), 934-948 (2007)

Dargay, J., Vythoulkas, P.: Estimation of a dynamic car ownership model: a pseudo-panel approach. J. Transp. Econ. Policy 33(3), 287-302 (1999)

Department of Communities and Local Government: English Indices of Deprivation 2010-Guidance Document. Department of Communities and Local Government, London, UK (2011)

Feldman, O., Simmonds, D., Zacharidis, V., Mackett, R., Bosredon, M., Richmond, E., Nicoll, J.: Simdelta - a microsimulation approach to household location modelling. Paper presented to the world conference on transport research 2007, June 24-28, University of California, Berkeley (2007)

Fried, M., Havens, J., Thall, M.: Travel Behaviour-a Synthesized Theory (Project 8-14 Final Report). Transportation Research Board, Washington, DC (1977)

Giele, J., Elder, G.: Methods of Life Course Research: Qualitative and Quantitative Approaches, 1st edn. Sage, London (1998)

Hanly, M., Dargay, J.: Car Ownership in Great Britain—a Panel Data Analysis. University College London, London (2000)

Lanzendorf, M.: Mobility biographies. A new perspective for understanding travel behaviour. Paper presented to the 10th international conference on travel behaviour research, 10 August 2003, Lucerne (2003)

Levine, S., Polak, J.: Factors associated with young adults delaying and forgoing driving licences: results from Britain. Traffic Injury Prevent. 15(8), 794-800 (2014)

Miller, E.: An integrated framework for modelling short and long run household decision making. In: Timmermans, H. (ed.) Activity Based Analysis, 1st edn, pp. 175-201. Elsevier Ltd., Oxford (2005)

Oakil, A., Ettema, D., Arentze, T., Timmermans, H.: Changing household car ownership level and life cycle events: an action in anticipation or an action on occurrence. Transportation 41, 889-904 (2014)

Potoglou, D., Susilo, Y.: Comparison of vehicle-ownership models. Transp. Res. Rec. 2076, 95-105 (2008)

Prillwitz, J., Harms, S., Lanzendorf, M.: Impact of life-course events on car ownership. Transp. Res. Rec. 1985, 71-77 (2006)

Rashidi, T., Mohammadian, A., Koppelman, F.: Modeling interdependencies between vehicle transaction, residential relocation and job change. Transportation 38, 909-932 (2011)

Roorda, M., Carrasco, J., Miller, E.: An integrated model of vehicle transactions, activity scheduling and mode choice. Transp. Res. B 43, 217-229 (2009)

Salomon, I.: Lifestyles-a broader perspective on travel behaviour. In: Carpenter, S., Jones, P. (eds.) Recent Advances in Travel Demand Analysis, 1st edn, pp. 290-310. Gower, Aldershot (1983)

Salvini, P.A., Miller, E.J.: ILUTE: an operational prototype of a comprehensive microsimulation model of urban systems. Netw. Spat. Econ. 5, 217-234 (2005)

Scheiner, J., Holz-Rau, C.: Changes in travel mode choice after residential relocation: a contribution to mobility biographies. Transportation 40(2), 431-458 (2013)

Sheffield Bus Partnership: Bus_-your second car. Sheffield Bus Partnership. http://www.yoursecondcar.com (2013). Accessed 24 April 2014

Simma, A., Axhausen, K.: Commitments and modal usage: an analysis of German and Dutch panels. Transp. Res. Rec. 1854, 22-31 (2003)

Thorgersen, J.: Understanding repetitive travel mode choices in a stable context: a panel study approach. Transp. Res. A 40, 621-638 (2006)

Van der Waerden, P., Timmermans, H., Borgers, A.: The influence of key events and critical incidents on transport mode choice switching behaviour: a descriptive analysis. Paper presented at 10th international conference on travel behaviour, Lucerne, Aug. 2003 (2003)

Verplanken, B., Aarts, H., Van Knippenberg, A.: Habit, information acquisition and the process of making travel mode choices. Eur. J. Soc. Psychol. 27, 539-560 (1997)

Yamamoto, T.: The impact of life-course events on vehicle ownership dynamics. Int. Assoc. Traffic Saf. Sci. 32(2), 34-43 (2008)

Ben Clark is a Research Fellow in the Centre for Transport and Society at the University of the West of England, Bristol. His research interests currently centre on travel behaviour, with a specific focus on the application of longitudinal research methods to exploring how and why travel behaviours change over the course of people's lives. 
Kiron Chatterjee is Associate Professor in Travel Behaviour at the Centre for Transport and Society at the University of the West of England, Bristol. He has twenty five years experience of transport research in the areas of road safety, traffic management and information systems, travel behaviour, transport modelling, evaluation studies and transport future scenarios. Kiron specialises in investigating the dynamics of travel behaviour and has developed innovative methods of collecting longitudinal data and analysing the data using advanced statistical modelling. This understanding is used to enhance the capability of forecasting future mobility and designing transport systems and services that meet the needs of users.

Steve Melia is Senior Lecturer in Transport and Planning at the Centre for Transport and Society at the University of the West of England, Bristol. His past research concerns the relationship between the built environment and travel behaviour, including the 'paradox of intensification' and 'filtered permeability'. He has also researched, taught and written on aspects of transport policy. He is author of the book "Urban Transport Without the Hot Air" published by UIT Cambridge in June 2015. 